etc. ; neither prin nor swelling ; tubercle bscilli found in urine. On cystoscopic examination: Dark red swollen mucous membxane round orifice of left ureter; urine from right, specific gravity 1020, normal ; left, 1005, containing pus. Treatment: Nephrectomy, and injections of taberculin. Result so far as known to date: Doing well (three months after operation).

CASE XXII.-Female, aged 28. Family history of tabercle present; left side. Early symptoms : Frequency of micturition etc.; neither pain nor swelling; tubercle bacilli found in urine On cystoscopic examination : Left ureteral orifice surrounded by swollen, woolly-looking mucous membrane; patches of redness on left side of bladder; urine from right, speciflc gravity 1020, normsl ; left, specific gravity 1005 , containing pus. Treat. ment: Nephrectomy by Dr. John Campbell. Result so far as known to date: Doing well (two months after operation).

CASE XXIIr.-Female, aged 31. Family history of tubercle absent; both kidneys affected. Early symptoms: Left-sided renal colic, and frequency of micturition; both kidneys enlarged; no tubercle bacilli found in urine. On cystoscopic examination: A large irregular ulcer at base of bladder; left ureteral orifice buried in this; right orifice just at edge of vlcer; under $\mathrm{CHCl}_{3}$ with catheters in ureters, no urine; even after injection of indigo-carmine none could be seen flowing into bladder. Result so far as known to date: In statu quo; had anuria for twenty-four hours after examination.

CASE XXIV.-Male, aged 23. Family history of tubercle present ; right side; Early symptoms: Right-sided renal colic; righ kichney enlarged ; tubercle bacilli was found in urine. On cystoscopic examination: Right ureteral orifice round, red and dilated; red patches in neighbourhood ; right ureter not catheterized; left, specific gravity under 1005, containing albumen. Treatment : Medical. Result so far as known to date: Going preatment: Medical.

\section{SUPRAPUBIC DRAINAGE OF THE BLADDER} AS AN ALTERNATIVE TO PROSTATECTOMY AND AS A RELIEF OPERATION.

By J. B. PIKE, M.R C.S.ENG. HONORARY SURGEON, LOUGHBOROUGH HOSPITAL.

Prostatrctomy in selected cases, performed by an operator who has ample experience, is doubtless a satisfactory measure. If a large margin of risk had not to be allowed for no surgeon would condemn a patient to the inconveniences of catheter life. Suprapubic drainage is a middle course, and in many things a middle course, avoiding Scylla and Charybdis, is advisable. In cases of cancer of the bladder radical removal is a thing to be eimed at, but how often does it succeed? The bladder is removed and the ureters are transplanted, either fin the abdominal wall or the rectum. In both methods the result is very doubtful, even though at first a good result may appear to have been gained. There are, however, some cases in which removal, either of the growth or the organ, seems hopeless; and here as a relief measure suprapubic drainage appears to have a valuable place. The two following cases illustrate these remarks :

\section{CASE I.}

J. M., a farmer, of good physique, aged 69 years, was admitted to the Loughborough Hospital on October 25th, 1904 . prostate and partiy to a very tight traumatic stricture of the membranous portion of the urethra. Catheterism was unsuccessful, and aspiration gave temporary relief. On the following day a puncture was made above the pubes with a trocar, and a Jacques catheter inserted through the cannula. The patient managed somehow to get this out in the night, and thus rendered cystotomy imperative under somewhat nnfavourthus rendered cystotomy imperative under somewhat anfavour-
able conditions. The bladder was stitched to the edges of the able conditions. The bladder was

wound and a large tube inserted. in consultation with Mr. Bond of Leicester, and the operation was not pressed. The patient decided against it. In about six weeks he returned to his home and drained the bladder with some sort of rubber tube for about two years.

Having allowed the sinus to close he came to the hospital with retention in March, 1907. Relief was given by aspiration, and he passed water by the natural channel with increasing difficulty until November, 1907, when he sent for me to visit him. The only thing to do was to reopen the bladder, and this was done through the scar tissue, partly by incision, partly by trocar, the cannula being retained. We made various experiments with silver tubes, and at last got one to our liking. Since that time there has been very little trouble with the water, and the general condition has for the most part been good, his life having been quite activ

\section{CASE II.}

This was a case of multiple papilloma above the trigone. An exploratory cystotomy was done by Mr. Bond. Owing to the multiple nature and situation of the growth, it was decided that nothing further could be done. As I felt persuaded that the frequent micturition would become very painful if the wound closed, I kept a rubber tube permanently in the bladder. The cystotomy was done in March, 1909, and for many months great relief was obtained.

In these very painful cases the alternative is a poor thing at best, but slight relief is something to the good, and it may be desirable that life should be prolonged. I think these cases may be taken in evidence of the value of suprapubic drainage of the bladder.

\section{THE INCIDENCE OF TUBERCULOSIS IN CHILDHOOD.*}

By Priv. Doz. Dr. FRANZ hambURger, VIENA.

Is conjunction with $R$. Monti, I have endeavoured, by extensive investigation, to determine the incidence of taberculosis among the children of Vienna. We adopted the method of examining only children who were suffering from acute infectious diseases (scarlatina and diphtheria). In this way we obtained material which represented fairly accurately the real state of child-life in Vienna. All the children were first tested by Pirquet's cutaneous reaction. Those reacting negatively were, after two days, subjected to a subcutaneous tuberculin injection of $1 \mathrm{mg}$. Those of the children who showed a distinct inflammatory reaction at the injection point of at least three days' duration, were looked upon as tuberculous, as well as those showing a positive reaction.

In this way Monti and I found that out of 532 patients suffering from diphtheria or scarlatina 271 reacted positively-that is, about 50 per cent.

\begin{tabular}{|c|c|c|c|c|c|c|c|}
\hline \multirow{3}{*}{$\begin{array}{c}\text { Out of } \\
\text { ", }\end{array}$} & \multicolumn{3}{|c|}{23 children in the } & \multicolumn{2}{|c|}{ lst year } & \multicolumn{2}{|c|}{0 reacted- } \\
\hline & 45 & ", & ", & 2nd & ", & 4 & ", \\
\hline & 56 & ", & ", & $3 r d$ & ," & 11 & $"$ \\
\hline " & 75 & $"$ & ", & 4th & ", & 24 & " \\
\hline " & 63 & " & $"$ & Gen & $"$ & 30 & $"$ \\
\hline , & 63 & ", & , & 6th & $"$, & 3. & $"$ \\
\hline ", & 46 & " & $"$ & Ten & " & 22 & $"$ \\
\hline$"$ & 35 & $"$ & 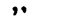 & oth & $"$ & 24 & $"$ \\
\hline$"$ & 36 & $"$ & $"$ & 10th & $"$ & 22 & $"$ \\
\hline$"$ & 29 & $"$ & $"$ & llth & 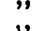 & 27 & ", \\
\hline$"$ & 19 & ", & ", & 12th & ," & 18 & ", \\
\hline ," & 17 & ," & ", & 13th & ," & 16 & ", \\
\hline , & & $\mu$ & , & & & 16 & \\
\hline
\end{tabular}

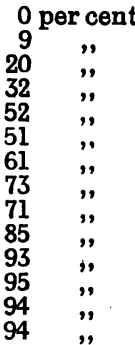

These results show how the frequency of tuberculosis in childhood increases from year to year. $t$ When child. hood is divided into six periods, the following percentages with regard to the frequency of the disease are obtained:
1. First year
2. Second year
3. Third to fourth year
4. Fifth to sixth year
5. Seventh to tenth year ...
6. Eleventh to fourteenth year

$\ldots .2$ per cent. +
$\ldots .9$
$\ldots .27$

It follows that nearly all persons in Vienna of over 14 years of age are already "tuberculous." This fact appears extraordinary and almost incredible. It is only appreciated when we investigate the fact further, and con sider that tuberculosis in childhood is a relatively harmless disease. It runs its course commonly without giving rise to any symptom. This explains the fact why so many children give a positive tuberculin reaction without at the same timo developing any stronger symptoms of disease. It may even be said that the majority of children who are only affected by tuberculosis after the fifth or sixth year show no signs, or at least very fow signs, of disease. That is the result of the constant increase of the frequency of tuberculosis on the one hand and the decrease of the tuberculous morbidity with increasing age on the other. This is further demonstrated by Pollak's clinical observations.

It must be fully understood that tuberculous infection and tuberculous morbidity are two conceptions which it is difficult to separate. While in the first, and also in the second, year the majority of children infected with tuber.

* Read at the Tuberculosis Conference, Edinburgh, July, 1910 t The percentage for the first year is not reliable, because the number of children examined (23) is too smoll. The real incidence of Cerculosis in this age, according to Sperk, is about 2 per cent.

t Corrected figure, according to sperk. 